\title{
Hemoptysis Hospital Based Study, At AL- Kindy Teaching Hospital
}

\author{
Baker Fadel, M.B.Ch.B. F.I.C.M.S. F.I.C.M.S(RES.), Ali Sajid M.B.Ch.B. F.I.C.M.S. Emad kareem Luaibi \\ M.B.CH.B.F.IC.M.S,F.I.C.M.S
}

\begin{abstract}
Background: Expectoration of blood that originated in the lungs or bronchial tubes is a frightening symptom for patients and often is a manifestation of significant and possibly dangerous underlying disease. Tuberculosis was and still one of the common causes followed by bronchiactasis, bronchitis, and lung cancer.
\end{abstract}

Objectives: The aim of this study is to find the frequency of causes of respiratory tract bleeding in 100 patients attending alkindy teaching hospital.

Type of the study: : Prospective descriptive observational study

Methods of a group of patients consist of one hundred consecutive adult patients, with Lower respiratory tract bleeding are studied. History, physical examination, and a group of selected investigations performed, including complete blood examination and blood film, PT, PTT, sputum direct gram and AFB stain, cytology ,chest radiography, CT scan, and bronchoscopy when indicated.

Results: pulmonary tuberculosis, acute bronchitis, lung carcinoma, and bronchectiasis are the major causes of hemoptysis in our study with $27 \%, 23 \%, 23 \%, 20 \%$ respectively. Of the included patients $63 \%$ were males, specially age $41-60$, while $37 \%$ were females. The primary malignancy is more common than secondary cancer, and that squamous cell carcinoma, and adenocarcioma, are the most common.

Conclusions: Tuberculosis is the main cause of lower respiratory tract bleeding, followed by lung carcinoma bronchitis, and bronchiactesis. Most of the patients are males and in middle age, sever bleeding is not common and squamous cell carcinoma is commonest cause regarding malignancies followed by adeno carcinoma.

Keywords: Hemoptysis, alkindy teaching hospital

\section{Al-Kindy College Medical Journal 2016: Vol. 12 No.2 Page: 56-59}

Received $26^{\text {th }}$ Oct 2015, accepted in final $22^{\text {th }}$ June 2016 Corresponding to: Baker fadel / Alkindy Teaching Hospital, email: bakerfm@yahoo.com,
Despiratory tract bleeding is a frightening symptom for patients and often is a manifestation of significant underlying disease. Hemoptysis (bleeding from respiratory tract) is the expectoration of blood that originated in the lungs or bronchial tubes. The patient's history should help determine the amount of blood and differentiate between hemoptysis, pseudohemoptysis, and hematemesis(1). A focused physical examination can lead to the diagnosis in most cases. In children, lower respiratory tract infection and foreign body aspiration are common causes .

In adults,tuberculosis, bronchitis, bronchectiasis ,bronchogenic carcinoma, and pneumonia are the major causes. Chest radiographs often aid in diagnosis and assist in using two complementary diagnostic procedures(2), fiberoptic bronchoscopy and highresolution computed tomography, which are useful in difficult cases and when malignancy is suspected. The goals of management are threefold: bleeding cessation, aspiration prevention, and treatment of the underlying cause. $(2,3)$.

Hemoptysis is also classified as nonmassive or massive based on the volume of blood loss; however, there are no uniform definitions for these categories.(2) hemoptysis is considered mild if blood loss is less than $200 \mathrm{~mL}$ per day.(3) moderate between $200-600 \mathrm{ml}$ ,massive more than $600 \mathrm{ml}$, life threating more than $1000 \mathrm{ml}$ per 24 hours (2) .
Common causes are;(2) Bronchiectasis (including cystic fibrosis), Tuberculosis, bronchial carcinoma, Nontuberculous mycobacteria, Lung abscess, Mycetoma (aspergilloma, or fungus ball), Pulmonary contusion or trauma. Uncommon causes are(2); Invasive aspergillosis or mucormycosis, Mitral stenosis, Pulmonary arteriovenous malformation, Bronchovascular fistula (eg, tracheobrachiocephalic artery fistula in patients with chronic tracheostomy), Bleeding diathesis, Foreign body, Idiopathic pulmonary hemosiderosis, Necrotizing bacterial pneumonia, Bronchial adenoma, Pulmonary embolism with infarction, Septic embolism from tricuspid endocarditis, Pulmonary-renal syndromes (Goodpasture's syndrome, systemic lupus erythematosus, Wegener's granulomatosis), Pulmonary artery rupture due to pulmonary arterial (Swan-Ganz) catheterization. Systemic causes of increase bleeding susceptibility must also be excluded.

The objective of this study is to find the frequency of causes of respiratory tract bleeding(hemoptysis) in 100 patients attending alkindy teaching hospital in the period jan. 2013 till march 2014.

Patients and Methods: Prospective descriptive observational study of a group of patients consist of one hundredconsecutiveadult patients, aged 21- 70 years both genders with Lower respiratory tract bleeding attending Alkindy Teaching hospital who visited 
outpatient clinic or admitted to medical ward in the periodJanuary 2013 till March 2014, are studied, mild hemoptysis; if blood loss is less than $200 \mathrm{~mL}$ per day. moderate between $200-600 \mathrm{ml}$,massive more than $600 \mathrm{ml}$, life threating more than $1000 \mathrm{ml}$ per 24 hours (2).Upper respiratory tract bleeding, gastrointestinalcauses excluded with the aid of specialists. Format paper arranged, contained detailed history, physical examination, and a group of selected investigations performed, including complete blood examination and blood film, PT, PTT, sputum direct gram and AFB (acid fast bacilli) stain, cytology ,chest radiography, CT scan, and bronchoscopy when indicated. Diagnosis established andstatistical analysis using tables and percentages are performed.Chest radiographs often aid in diagnosis and assist in using two complementary diagnostic procedures ${ }^{2}$, fiberoptic bronchoscopy and high-resolution computed tomography, which are useful in difficult cases and when malignancy is suspected. The role of flexible versus rigid bronchoscopy in massive hemoptysis has been debated, as has the role of medical versus surgical therapy. Many case series comparing medical and surgical treatment have had serious selection biases.

Results: Distribution of patients with hemoptysis reveals that pulmonary tuberculosis, acute bronchitis, lung carcinoma, and bronchectiasis are the major causes of hemoptysis in our study with $27 \%, 23 \%, 23 \%, 20 \%$ respectively. (Table.1) Most patients with pulmonary tuberculosis had mild hemoptysis while most of the patients with bronchectiasis had moderate hemoptysis. Overall, the study showed that most of patients had mild hemoptysis $(74 \%)$ and that massive hemoptysis were uncommon $4 \%$ in the patients studied. Regarding the Gender of the patients the study showed that $63 \%$ of the included patients were male, specially age $41-60$, while $37 \%$ were female. Distribution of the patients according age group showed that the great bulk of the patients in middle age between $41-60$ years $54 \%$ (table 2 ).

Type of malignancies associated with hemoptysis showed that the primary malignancy is more common than secondary cancer, and that squamous cell carcinoma, and adenocarcioma, are the most common (about $35 \%$, and $22 \%$ respectively), while most of the secondariescames from the breast (table 3 ).

\begin{tabular}{|c|c|c|c|c|c|}
\hline Diagnosis & $\begin{array}{l}\text { Tota } \\
\text { I }\end{array}$ & $\begin{array}{l}\text { Mil } \\
\text { d }\end{array}$ & $\begin{array}{l}\text { Moderat } \\
\text { e }\end{array}$ & $\begin{array}{l}\text { Sever } \\
\mathrm{e}\end{array}$ & $\begin{array}{l}\text { percenta } \\
\text { ge }\end{array}$ \\
\hline Tuberculosis & 27 & 20 & 6 & 1 & $27 \%$ \\
\hline Lung carcinoma & 23 & 18 & 4 & 1 & $23 \%$ \\
\hline $\begin{array}{l}\text { Acute/chronic } \\
\text { bronchitis }\end{array}$ & 23 & 23 & 0 & 0 & $23 \%$ \\
\hline Bronchiectasis & 20 & 8 & 11 & 1 & $20 \%$ \\
\hline Mitral stenosis & 4 & 3 & 1 & 0 & $4 \%$ \\
\hline $\begin{array}{l}\text { Congestive } \\
\text { heart failure }\end{array}$ & 1 & 1 & 0 & 0 & $1 \%$ \\
\hline $\begin{array}{l}\text { Haemorghicdise } \\
\text { ases }\end{array}$ & 2 & 1 & 0 & 1 & $2 \%$ \\
\hline Total & 100 & 74 & 22 & 4 & $100 \%$ \\
\hline
\end{tabular}

Table 1. Distribution of hemoptysis according to the causes

Table 2 Distribution of patients according to age and gender

\begin{tabular}{|l|l|l|l|}
\hline $\begin{array}{l}\text { Age } \\
\text { /years }\end{array}$ & No. & Male & Female \\
\hline $21-30$ & 16 & 9 & 7 \\
\hline $31-40$ & 15 & 11 & 4 \\
\hline $41-50$ & 19 & 10 & 9 \\
\hline $51-60$ & 35 & 24 & 11 \\
\hline $61-70$ & 15 & 9 & 6 \\
\hline Total & 100 & 63 & 37 \\
\hline
\end{tabular}

Table 3 Distribution of patients according to type of cancer

\begin{tabular}{|l|l|l|}
\hline Cancer type & No. & Percentage\% \\
\hline Primary ca lung & 16 & 69.5 \\
\hline Squamous cell ca & 8 & 34.8 \\
\hline Adenoca & 5 & 21.7 \\
\hline Small cell ca & 3 & 13 \\
\hline Secondary ca & 7 & 30.5 \\
\hline Breast ca & 4 & 17.4 \\
\hline Laryngeal ca & 2 & 8.7 \\
\hline Others & 1 & 4.3 \\
\hline Total & 23 & $100 \%$ \\
\hline
\end{tabular}


Discussion: Lower respiratory tract bleeding is a frightening symptom for patients and often is a manifestation of significant and possibly dangerous underlying disease.

Santiago et.al report that the prevalence of causes of hemoptysis as follow; bronchogenic carcinoma (29\%), bronchitis (23\%), and idiopathic hemoptysis (22\%) accounted for the majority of causes of hemoptysis. In contrast to older studies, the incidence of hemoptysis secondary to tuberculosis and bronchiectasis has decreased. Although patient population is predominantly male and elderly, these data may well be representative of more recent epidemiologic trends in causes of hemoptysis.(4) In Singapore (south east asia) The most common causes of haemoptysis were pulmonary tuberculosis and post-tuberculous bronchiectasis(5).In the present study; tuberculosis still a common cause of hemoptysis in iraq which possibly reflects the high incidence in the community.

More recently in well developed countries, bronchiectasis $(20 \%)$, lung cancer $(19 \%)$, bronchitis (18\%), and pneumonia (16\%) accounted for most causes of hemoptysis. In contrast to older studies, active tuberculosis was a rare finding (1.4\%). Bronchiectasis and bleeding diathesis were major causes of moderate to severe hemoptysis while bronchitis and lung cancer were commonly associated with milder degrees of bleeding.(6) And in other study from tertiary referral hospital by Tsoumakidou et.al, the main causes of hemoptysis were bronchiectasis (26\%), chronic bronchitis (23\%), acute bronchitis (15\%) and lung cancer (13\%).(7) While in this study bronchogenic carcinoma, bronchitis, and bronchiactasis, while still common causes of hemoptysis but occur less often than tuberculosis.

Sever (massive) hemoptysis, a critical amounts have ranged from 200 to greater than $600 \mathrm{ml}$ in 24 hours(8), occurs in less than $5 \%$ of patients with hemoptysis and is almost always due to serious pulmonary or systemic illness.(9)Severe haemoptysis was related mainly to the bronchial artery (82\%), and major pulmonary artery involvement was rare (6.4\%).(10) In the present study massive or sever hemoptysis occur in $4 \%$ and moderate in $22 \%$ of cases also.Conservative medical therapy may suffice in certain conditions, like bronchiectasis, coagulopathies, and acute bronchopulmonary infections. Preparation for other interventions should be undertaken if the bleeding notrespond to conservative therapy. Supportive therapy should be applied to all patients with sever hemoptysis.(11)

Unsal et.alstudy,show that those patients with hemoptysis had mean age of 48(SD 17) years, (106 males, 37 females). Bronchiectasis was the most common cause of hemoptysis $(22.4 \%)$, followed by lung cancer $(18.9 \%)$, active tuberculosis $(11.2 \%)$, and inactive tuberculosis (10.5\%).(12) In other study of a total of 178 patients 136 male, 42 female were found(13). The average age was 46.4 years old (age brackets: 18 to 84 years).(14) In the present study males more affected than females, and hemoptysis presentation occur in middle age group as had been seen in other studies.

In the present study just less than quarter of cases of hemoptysis are due to lung malignancy, $70 \%$ of it are bronchogenic carcinoma, where squamous cell carcinoma found to be most common followed by adenocarcinoma. In a study by João Adriano et.al(15), $35 \%$ of patient with lung cancer presented with hemoptysis. Most cases of lung cancer are diagnosed when the disease is already at a locally advanced or metastatic stage, which has a negative impact on the prognosis.(16) Indeed Non-small cell lung cancer is the most common type of lung cancer, representing more than $80 \%$ of lung cancer diagnoses.(17) And althoughadeno carcinoma is more common than squamous cell and small cell(18), in the present study squamous cell type is more commonly presented with hemoptysis.

Conclusion: Tuberculosis is the main cause of lower respiratory tract bleeding, followed by lung carcinoma bronchitis, and bronchiactesis. Most of the patients are males and in middle age, sever bleeding is not common and squamous cell carcinoma is commonest cause regarding malignancies followed by adeno carcinoma.

\section{References}

1-Thompson $A B$, et, al. Pathogenesis, evaluation, and therapy for massive hemoptysis. ClinChest Med 1992; 13:69-82.

2-Hirshberg B, et,al. Hemoptysis: etiology, evaluation, and outcome in a tertiary referral hospital. Chest. $1997 ; 112: 440$

3-Knott-Craig CJ,et al. Management and prognosis of massivehemoptysis. ThoracicCardiovasc

Surg. 1993;105:394-7.

4-Santiago S1, Tobias J, Williams AJ. A reappraisal of the causes of hemoptysis.

Arch Intern Med. 1991 Dec;151(12):2449-51.

5-Stebbings AE, Lim TK. Cause, treatment and outcome of patients with life-threatening haemoptysis. Singapore Med J. 1999 Feb;40(2):67-9.

6-Hirshberg B, Biran I, Glazer M, Kramer MR. Hemoptysis: etiology, evaluation, and outcome in a tertiary referral hospital. Chest. 1997 Aug;112(2):440-4.
7-Tsoumakidou
M, Chrysofakis
$\mathrm{G}$, Tsiligianni

I, Maltezakis G, SiafakasNM, Tzanakis N. A prospective analysis of 184 hemoptysis cases: diagnostic impact of chest X-ray, computed tomography, bronchoscopy.Respiration. 2006;73(6):808-14.

8-olfe JD, Simmons DH: Hemoptysis: Diagnosis and management (Medical Progress). West J Med 127:383390, Nov 1977

9-Johnson JL. Manifestations of hemoptysis. How to manage minor, moderate, and massive bleeding.Postgrad Med. 2002 Oct;112(4):101-6, 108-9, 113. 
10Keyvan Razazi, Antoine Parrot, Antoine Khalil, Michel Djibre, Valerie Gounant, Jalal Assouad, Marie

France Carette, Muriel Fartoukh, Jacques Cadrane.

Severe haemoptysis in patients with nonsmall cell lung carcinoma.European respiratory journal.1 jan 2014 Vol 46 Issue 4.

11- Jean-Baptiste, Eddy. Clinical assessment and management of massive hemoptysis. Critical Care Medicine:May 2000 - Volume 28 - Issue 5 - pp 16421647.

12-Unsal E, Köksal D, Cimen F, TaciHoca N, Sipit T . Analysis of patients with hemoptysis in a reference hospital for chest diseases. TuberkToraks. 2006;54(1):34-42.

13-Uzun O1, Atasoy Y, Findik S, Atici AG, Erkan L. A prospective evaluation of hemoptysis cases in a tertiary referral hospital. ClinRespir J. 2010 Jul;4(3):131-8.
14Hanane Benjelloun, Nahid Zaghba, Abdelaziz Bakhat ar, Najiba Yassine, Abdelkrim Bahlaoui. Etiologic and prognostic profile of the hemoptysis . 1 sep 2012 European respiratory journal vol 40 issue 56 .

15-João Adriano Barros Geraldo Valladares, Adriane Reichert Faria, Erika Megumi Fugita, Ana Paula Ruiz, André Gustavo DaherVianna, GuilhermeLuísTrevisan, Fabrício Augusto Martinelli de Oliveira. Early diagnosis of lung cancer: the great challenge. Epidemiological variables, clinical variables, staging and treatmen. J. bras. pneumol. vol.32 no.3 São Paulo May/June 2006. 16-Daniel C. Lung cancer, a worrying epidemiological evolution. Rev Infirm. 2012 Oct;(184):14-6.

$17-$ Walker S. Updates in non-small cell lung cancer. Clin J OncolNurs. 2008 Aug;12(4):587-96

18-Alberg AJ, Samet JM (2010). "Chapter 46". Murray \&Nadel's Textbook of Respiratory Medicine (5th ed.). Saunders Elsevier. ISBN 978-1-4160-4710-0. 